\title{
Log-domain Universal Biquad Filter Design Using Lossy Integrators
}

\author{
Niyazi Duduk ${ }^{1}$, Abdullah T. Tola ${ }^{2}$ \\ ${ }^{I}$ Department of Electronics and Automation, Denizli Vocational School of Technical Sciences, \\ Pamukkale University, \\ 20160 Kinikli, Denizli, Turkey \\ ${ }^{2}$ Department of Electrical-Electronics Engineering, Faculty of Engineering, Pamukkale University, \\ 20160 Kinikli, Denizli, Turkey \\ attola@pau.edu.tr
}

\begin{abstract}
In this paper, a new current mode low voltage log domain Class A universal biquad filter is proposed. The proposed circuit is derived from the block diagram based on Kerwin-Huelsman-Newcomb (KHN) circuit using lossy integrators. The circuit can provide second-order low pass, band pass and high pass filter characteristics. State space method and translinear principle is used for circuit synthesis. The natural frequency $f_{0}$ and quality factor $Q$ of the circuit is electronically tunable by varying amplitudes of the current sources. PSpice simulation results are given in order to verify the theoretical analysis. The simulations are performed with both ideal transistor models and AT\&T CBIC-R type real transistor models.
\end{abstract}

Index Terms-Active filters; analog circuits; bipolar transistor circuits; current-mode circuits.

\section{INTRODUCTION}

The Kerwin-Huelsman-Newcomb (KHN) biquad has low sensitivity performance, low component spread and good stability characteristics [1], [2]. Two lossless integrators with feedback loops and a summer block establishes the classical KHN circuit that can function as three fundamental filters; low pass, high pass and band pass filters. There are many KHN biquad filters have been proposed in the literature synthesized by both voltage mode and current mode synthesis methods [3]-[12].

Current-mode operation offers greater linearity, lower power consumption and a wider bandwidth than voltagemode operation counterparts [8]. Log domain filters are known as new generation current mode circuits which have drew attention of investigators since a general state space synthesis method had been proposed by Frey [13], [14]. Log domain filters are an important alternative because they have low voltage, low power consumption, high linearity and electronically tunable characteristics in continuous time active filter design [15], [16]. Log domain circuits are in the category of Externally Linear Internally Nonlinear (ELIN)

Manuscript received 25 September, 2015; accepted 26 February, 2016

This work is based on work supported by Scientific Research Projects Coordination Unit of Pamukkale University, under Project number of 2015 FBE027. circuits [17]. Based on the principles of translinear circuits, the operations in log domain circuits are nonlinear, while the transfer function is kept to be linear [13], [17].

Log domain filters use companding in signal processing idea [18], [19]. The input current is compressed by a logarithmic function using a bipolar transistor. A bipolar transistor's emitter-base voltage is logarithm of the current of the device. The output voltage is expanded by applying the signal to a bipolar transistor's base-emitter junction. The output current is exponential of the output voltage. The transfer function is linear because output function is the reverse function of the input function. Companding in signal processing offers a large scale of dynamic range [19].

The aim of this study is to gain the advantages of KHN circuit structure, log-domain characteristics and companding idea listed above. The major difference of the proposed circuit from original KHN structure is lossy integrators that are used for our design.

The proposed circuit in this work is designed for Class A operations. There are various works for Class A and Class AB log domain filter circuits in the literature [20]-[24].

In this paper, a new current mode log domain Class A universal filter based on KHN biquad is synthesized by using the state-space synthesis method [13], [15].

\section{DESIGN}

The original KHN biquad circuit consists of integrator blocks, summer blocks and feedbacks. The idea of modifying KHN block diagram by using lossy integrators is proposed by R. Arslanalp [25]. By using this idea, the proposed block diagram is shown in Fig. 1. Proposed work handles this block diagram and it is synthesized in log domain in order to gain advantages of log domain. In the block diagram, $y_{\mathrm{LP}}, y_{\mathrm{HP}}, y_{\mathrm{BP}}$ yields to low pass filter output, high pass filter output and band pass filter output respectively:

$$
\begin{gathered}
y_{1}=u+\left(2-\frac{1}{Q}\right) y_{2}-\left(2-\frac{1}{Q}\right) y_{L P}, \\
y_{2}=\frac{\omega_{0}}{s+\omega_{0}} y_{1}
\end{gathered}
$$




$$
\begin{gathered}
y_{L P}=\frac{\omega_{0}}{s+\omega_{0}} y_{2}=\frac{\omega_{0}^{2}}{s^{2}+\frac{\omega_{0}}{Q} s+\omega_{0}^{2}} u, \\
y_{H P}=u-y_{2}+\left(1-\frac{1}{Q}\right) y_{B P}=\frac{s^{2}}{s^{2}+\frac{\omega_{0}}{Q} s+\omega_{0}^{2}} u, \\
y_{B P}=y_{2}-y_{L P}=\frac{\omega_{0} s}{s^{2}+\frac{\omega_{0}}{Q} s+\omega_{0}^{2}} u .
\end{gathered}
$$

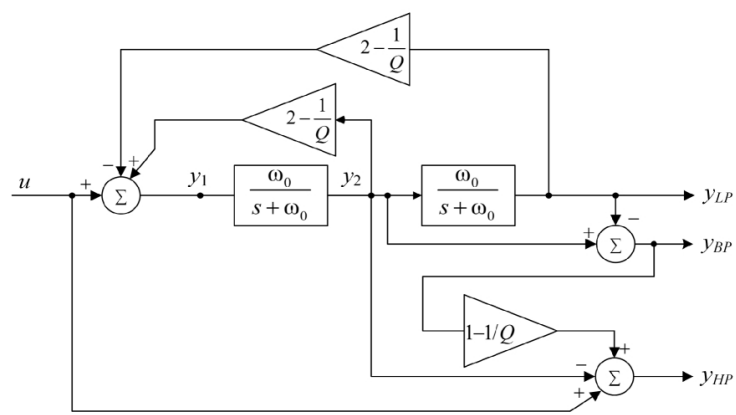

Fig. 1. Proposed universal biquad filter block diagram [20].

\section{LOSSY INTEGRATOR}

Realization of the lossy integrator and multiplier blocks are needed to design the Class A log domain circuit based on Fig. 1. The circuit is operating in current-mode so there is no need to design current summer blocks.

The log domain lossy integrator design procedure is the first step. The lossy integrator block will be synthesized by general state-space method of Class A log domain circuits explained in [13], [21]. Let the following transfer function to establish the lossy integrator

$$
H(s)=\frac{y(s)}{u_{0}(s)}=\frac{\omega_{0}}{s+\omega_{0}},
$$

where $\omega_{0}$ is the cut off frequency of the filter.

The state space representations of (6) are shown below:

$$
\begin{gathered}
\dot{x}=-\omega_{0} x+\omega_{0} u_{0}, \\
y=x,
\end{gathered}
$$

where $x$ is the state variable, $u_{0}$ is the input, $y$ is the output. Suppose that the following mapping functions are applied to the state and input variables:

$$
\begin{gathered}
u_{0}=I_{s} e^{v_{0} / V t}, \\
x=I_{s} e^{v_{1} / V t} .
\end{gathered}
$$

By using (7)-(10) and multiplying with

$$
\frac{C V_{t}}{I_{s} e^{v_{1} / V_{t}}} \text {. }
$$

we have:

$$
C \dot{v}_{1}=-I_{f}+I_{f} e^{\left(v_{0}-v_{1}\right) / V_{t}}
$$

$$
y=I_{s} e^{v_{1} / V_{t}}
$$

where $I_{f}=\omega_{0} C V_{t}$, and $V_{t}$ is the thermal voltage of the transistor.

(12) can be written as follows

$$
C \dot{v}_{1}=-I_{f}+I_{s} e^{\left(v_{0}+V_{f}-v_{1}\right) / V_{t}} .
$$

where $V_{f}=V_{t} \ln \left(\frac{I_{f}}{I_{s}}\right)$.

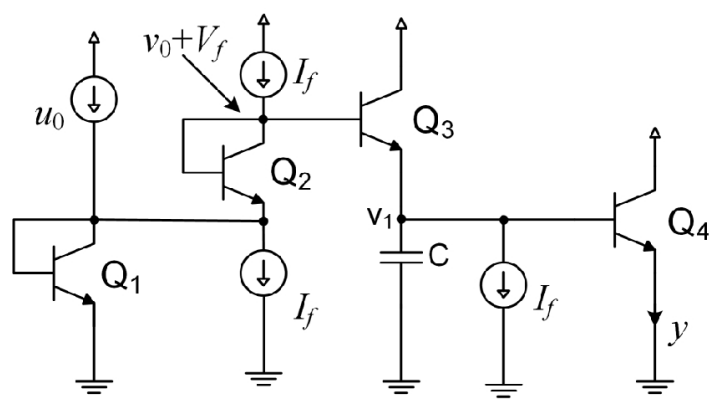

Fig. 2. First order Class A log domain lossy integrator.

The left side of the (14) can be considered as a grounded capacitor's current which is connected to the node that has voltage of $v_{1}$. The right side of (14) can be realized by a current source and a bipolar transistor that its base is connected to the node which has a voltage of $v_{0}+V_{f}$ and its emitter is connected to the node which has a voltage of $v_{1}$. The circuit synthesized with these considerations is shown in Fig. 2.

\section{CURRENT MULTIPLIER}

The second step is synthesizing a current multiplier. The circuit design procedure is based on translinear principle [26]. The following equation defines the current multiplier block

$$
i_{O U T}=\frac{I_{D C 1}}{I_{D C 2}} i_{I N} .
$$

The realization of current multiplier circuit based on translinear principle is shown in Fig. 3.

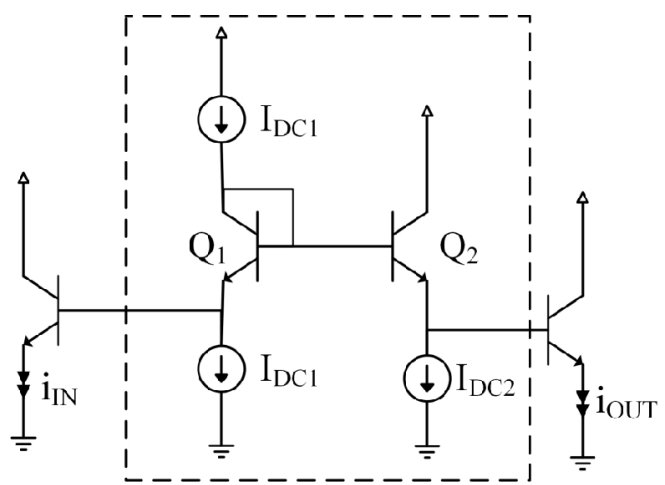

Fig. 3. Current multiplier circuit.

By using the designed circuits in Fig. 2 and Fig. 3 in the block diagram of Fig. 1, the whole circuit designed shown in Fig. 4. 


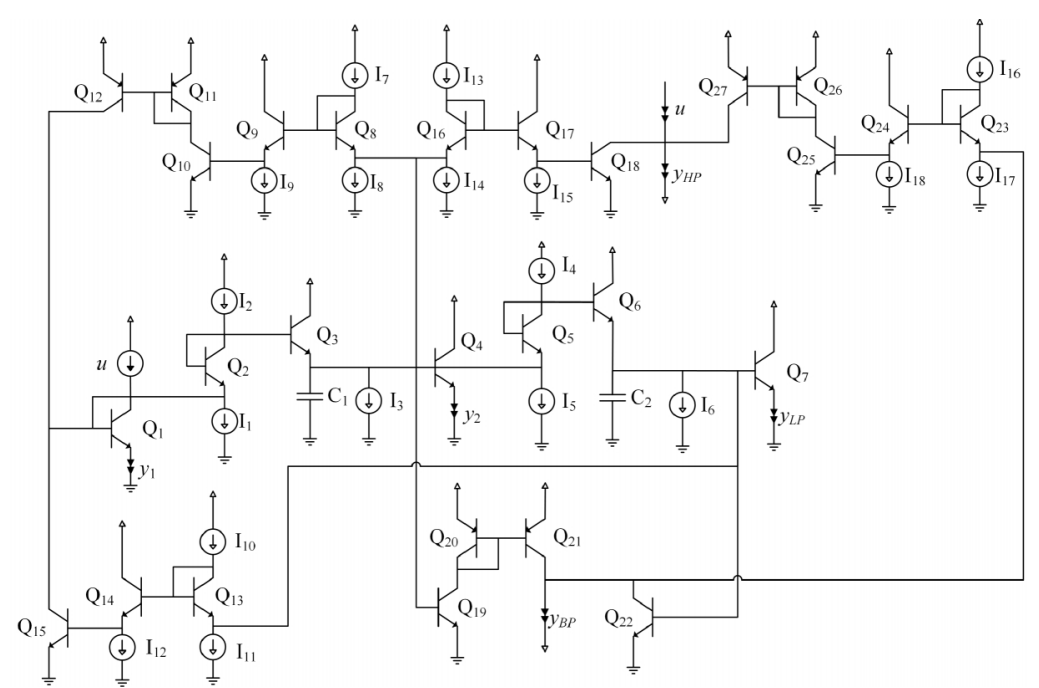

Fig. 4. Class A log domain universal biquad filter.

\section{Simulation Results}

The designed log domain universal biquad filter is simulated in PSpice by using ideal transistors that are default BJT models with $\mathrm{BF}=10000$. This simulation is made to check whether results obtained from theoretical works and simulation results are in agreement. Input current $u$ consists of DC and sinusoidal parts because of the Class A operation. DC part of the input is set to be $I_{f}$, the sinusoidal part is set to be $0.1 I_{f}$. The supply voltage is $2.25 \mathrm{~V}$. The values of capacitances of lossy integrators are chosen to be $C_{1}=C_{2}=$ $24.6 \mathrm{nF}$. The values of current sources $I_{1}-I_{6}, I_{9}, I_{12}-I_{18}$ are set to be $I_{f} ; I_{7}, I_{8}, I_{10}, I_{11}$ are set to be $(1-1 / Q) I_{f}$ where $I_{f}=$

$500 \mu \mathrm{A}$. This yields a pole frequency of $f_{0}=125 \mathrm{kHz}$ for PSpice simulations whereas calculated value of this parameter from $I_{f}=\omega_{0} C V_{t}$ is also $f_{0}=125 \mathrm{kHz}$. The simulation results are in agreement with theoretical results so the next step is to perform simulations by using AT\&T CBIC-R type real transistor models in [13]. Because of the nonlinearities of the real transistor models, the current gain values of some blocks in Fig. 1 are lower than expected. To overcome this problem, some transistors' area values and some current sources' values are slightly modified.

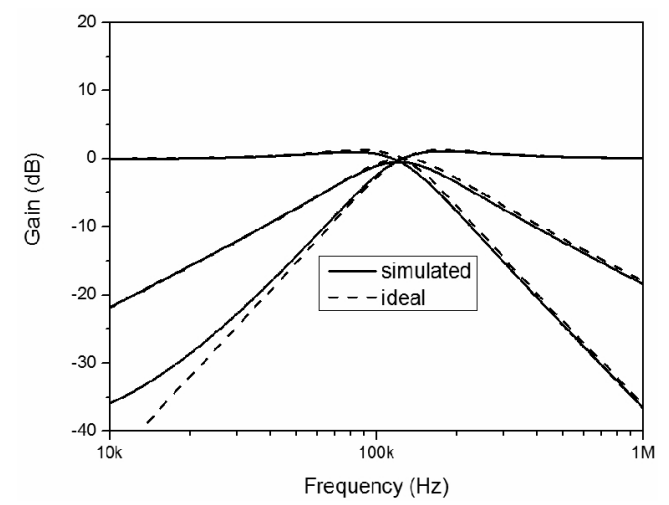

Fig. 5. Fundamental filters' gain responses.

The first simulation is performed for AC response of the circuit with pole frequency of $f_{0}=122 \mathrm{kHz}$ and quality factor $Q=1$. The filter responses of all fundamental filter characteristics are obtained. The gain characteristics of fundamental filter responses (lp, $h p$ and $b p)$ are given in Fig. 5. The figure shows that the ideal and the simulated results are in accordance with each other. The pole frequency and the quality factor is adjustable by varying values of the current sources. These characteristics give us the advantage of using this circuit for wide frequency areas without any modification on circuit structure. In Fig. 6 the quality factor $Q$ is electronically set to 2 . If $Q$ is set greater than 2 , the difference between simulations with ideal models and real models gets higher due to circuit limitations. In Fig. 7 it is shown that the center frequency $f_{0}$ is swept two decades by only varying the values of current sources which $I_{f}$ is set to $5 \mu \mathrm{A}$ for $f_{0}=1.3 \mathrm{kHz}, I_{f}$ is set to $50 \mu \mathrm{A}$ for $f_{0}=$ $13 \mathrm{kHz}, I_{f}$ is set to $500 \mu \mathrm{A}$ for $f_{0}=122 \mathrm{kHz}$ where the amplitude of the sinusoidal part of input signal is set to $0.1 I_{f}$.

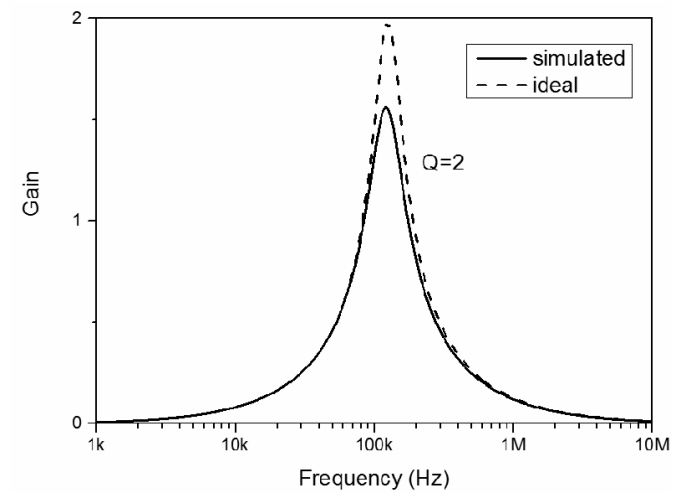

Fig. 6. Tunable $Q$ for band pass filter.

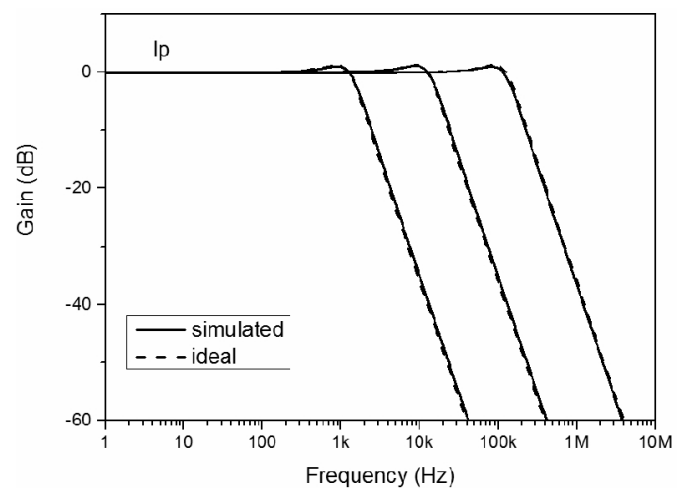

Fig. 7. Tunable $f_{0}$ for low pass filter. 


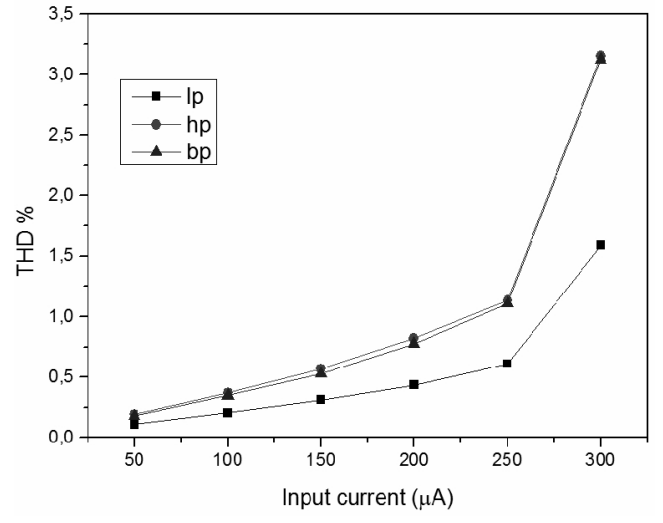

Fig. 8. THD values.

THD of the output signal was measured for all filter responses for some input current values. The results are shown in Fig. 8. DC offset of the input $u$ is set to $500 \mu \mathrm{A}$, sinusoidal part of input signal is swept from $50 \mu \mathrm{A}$ to $300 \mu \mathrm{A}$.

\section{CONCLUSIONS}

In this study, a Class A log domain filter based on KHN structure is designed to obtain low pass, high pass and band pass filter characteristics. It is the first time that lossy integrators are used to design this type of filter circuit. Lossy integrator block and multiplier block have been synthesized in order to realize the circuit. Lossy integrator block is synthesized by state space synthesis method and translinear circuit theory. Multiplier block is also synthesized by translinear circuit theory. The filter's quality factor $Q$ and the pole frequency $f_{0}$ is electronically tunable by only varying values of the DC current sources. The circuit can perform universal filter responses namely low pass, high pass and band pass. The filter circuit is simulated in PSpice by using both ideal and real transistor models. The simulation results verify the validity of the designed circuit. Both time domain and frequency domain results show that the designed filter has the advantages of electronic tunability of quality factor $Q$, the pole frequency $f_{0}$ and also the good stability behavior of KHN structure.

\section{REFERENCES}

[1] W. J. Kerwin, L. P. Huelsman, R. W. Newcomb, "State-variable synthesis for insensitive integrated circuit transfer functions", IEEE $J$. Solid-State Circuits, vol. 2, no. 3, pp. 87-92, 1967. [Online] Available: http://dx.doi.org/10.1109/JSSC.1967.1049798

[2] A. S. Sedra, K. C. Smith, Microelectronic Circuits. New York: Oxford University Press, 2009, ch. 16.

[3] K. N. Salama, A. M. Soliman, "Voltage mode Kerwin-HuelsmanNewcomb circuit using CDBAs", Frequenz, vol. 54, pp. 90-93, 2000.

[4] M. A. Ibrahim, H. Kuntman, "A novel high CMRR high input impedance differential voltage-mode KHN-biquad employing DODDCCs", AEU - Int. J. Electron. Commun., vol. 58, no. 6, pp. 429433, 2004. [Online]. Available: http://dx.doi.org/10.1078/1434-841154100266

[5] A. S. Sedra, K. C. Smith, "A second-generation current conveyor and its applications", IEEE Trans. Circuit Theory, vol. 17, no. 1, pp. 132-134, 1970. [Online]. Available: http://dx.doi.org/10.1109/ TCT. 1970.1083067

[6] A. M. Soliman, "Kerwin-Huelsman-Newcomb circuit using current conveyors", Electron. Lett., vol. 30, no. 24, pp. 2019-2020, 1994.
[Online]. Available: http://dx.doi.org/10.1049/el:19941368

[7] R. Senani, V. K. Singh, "KHN-equivalent biquad using current conveyors", Electron. Lett., vol. 31, no. 8, pp. 626-628, 1995. [Online]. Available: http://dx.doi.org/10.1049/el:19950422

[8] A. Toker, S. Ozoguz, C. Acar, "Current-mode KHN-equivalent biquad using CDBAs", Electron. Lett., vol. 35, no. 20, p. 1682, 1999. [Online]. Available: http://dx.doi.org/10.1049/el:19991179

[9] E. Altuntas, A. Toker, "Realization of voltage and current mode KHN biquads using CCCIIs," AEU - Int. J. Electron. Commun., vol. 56, no. 1, pp. 45-49, 2002. [Online]. Available: http://dx.doi.org/ 10.1078/1434-8411-54100071

[10] M. A. Ibrahim, S. Minaei, H. Kuntman, "A 22.5MHz current-mode KHN-biquad using differential voltage current conveyor and grounded passive elements", AEU - Int. J. Electron. Commun. vol. 59, no. 5, pp. 311-318, 2005. [Online]. Available: http://dx.doi.org/10.1016/j.aeue.2004.11.027

[11] A. U. Keskin, D. Biolek, E. Hancioglu, V. Biolkova, "Current-mode KHN filter employing current differencing transconductance amplifiers", AEU - Int. J. Electron. Commun., vol. 60, no. 6, pp. 443-446, 2006. [Online]. Available: http://dx.doi.org/10.1016/ j.aeue.2005.09.003

[12] A. T. Tola, R. Arslanalp, S. Surav Yilmaz, "Current mode highfrequency KHN filter employing differential class $\mathrm{AB} \log$ domain integrator", AEU - Int. J. Electron. Commun., vol. 63, no. 7, pp. 600608,2009 . [Online]. Available: http://dx.doi.org/10.1016/j.aeue. 2008.04.015

[13] D. R. Frey, "Log-domain filtering: an approach to current-mode filtering", Circuits, Devices Syst. IEE Proc. G, vol. 140, no. 6, pp. 406-416, 1993.

[14] D. R. Frey and L. Steigerwald, "An adaptive analog notch filter using log filtering", in 1996 IEEE Int. Symposium on Circuits and Systems. Circuits and Systems Connecting the World, (ISCAS 1996), 1996, vol. 1, pp. 297-300. [Online]. Available: http://dx.doi.org/10.1109/ iscas. 1996.539888

[15] D. R. Frey, "Exponential state space filters: a generic current modedesign strategy", IEEE Trans. Circuits Syst. I Fundam. Theory Appl., vol. 43, no. 1, pp. 34-42, 1996.

[16] M. Punzenberger, C. Enz, "Log-domain filters for low-voltage lowpower applications", in 1998 IEEE Int. Conf. Electronics, Circuits and Systems. Surfing the Waves of Science and Technology (Cat. No.98EX196), 1998, vol. 1, pp. 41-44. [Online]. Available: http://dx.doi.org/10.1109/icecs.1998.813267

[17] Y. Tsividis, "Externally linear, time-invariant systems and their application to companding signal processors", IEEE Trans. Circuits Syst. II Analog Digit. Signal Process., vol. 44, no. 2, pp. 65-85, 1997. [Online]. Available: http://dx.doi.org/10.1109/82.554425

[18] Y. P. Tsividis, V. Gopinathan, L. Toth, "Companding in signal processing”, Electron. Lett., vol. 26, no. 17, p. 1331, 1990. [Online]. Available: http://dx.doi.org/10.1049/el:19900858

[19] E. Seevinck, "Companding current-mode integrator: A new circuit principle for continuous-time monolithic filters", Electron. Lett., vol. 26, no. 24, p. 2046, 1990. [Online]. Available: http://dx.doi.org/ 10.1049/el: 19901319

[20] A.T. Tola, R. Arslanalp, S. S. Yilmaz, "Current mode tow-thomas biquadratic differential class $\mathrm{AB} \log$ domain filter", Int. Review of Electrical Engineering (IREE), vol. 4, no 6, pp. 1426-1432, 2009.

[21] N. Duduk, A. T. Tola, "A study about effects of transistors' nonideal characteristics on log domain filters", in Applied Electronics (AE), 2012 Int. Conf., 2012, pp. 69-74.

[22] A. T. Tola, D. R. Frey, "A study of different class AB log domain first order filters", Analog Integrated Circuits and Signal Processing, vol. 550, pp. 57-70, 2000. [Online]. Available: http://dx.doi.org/ 10.1007/978-1-4757-6414-7_4

[23] A. T. Tola, S. S. Yilmaz, R. Arslanalp, "Current mode log domain notch filter design based on adding filtering blocks", Electronics World, vol. 116, no. 1896, pp. 42-44, 2010.

[24] R. Arslanalp, S. S. Yilmaz, A. T. Tola, "Log domain hybrid design: block model and state space synthesis", Electronics World, vol. 116, no. 1887 , pp. $44-46,2010$.

[25] R. Arslanalp, "Synthesis of electronically tunable analog functional blocks", Ph.D. dissertation, Dept. of Electrical-Electronics Eng., Pamukkale Univ., Denizli, 2011.

[26] B. Gilbert, "Translinear circuits: a proposed classification", Electron. Lett., vol. 11, no. 1, p. 14, 1975. [Online]. Available: http://dx.doi.org/10.1049/el:19750011 